\title{
Using Infrared Radiation in a Radiant Wall Oven for Blanching Small-Sized Peanuts
}

\author{
Catherine Smith, ${ }^{1}$ Koushik Adhikari ${ }^{D},{ }^{2}$ and Rakesh K. Singh ${ }^{1}$ \\ ${ }^{1}$ Food Science \& Technology, University of Georgia, Athens, GA 30605, USA \\ ${ }^{2}$ Food Science \& Technology, University of Georgia, Griffin, GA 30223, USA \\ Correspondence should be addressed to Koushik Adhikari; koushik7@uga.edu
}

Received 29 October 2017; Revised 22 December 2017; Accepted 4 January 2018; Published 31 January 2018

Academic Editor: Ángel A. Carbonell-Barrachina

Copyright (c) 2018 Catherine Smith et al. This is an open access article distributed under the Creative Commons Attribution License, which permits unrestricted use, distribution, and reproduction in any medium, provided the original work is properly cited.

\begin{abstract}
The main objective of this study was to determine the effectiveness of infrared technology for blanching small-sized peanuts. A radiant wall oven was used for infrared blanching. Infrared treatments included $343^{\circ} \mathrm{C}$ for $60 \mathrm{~s}$ and $288^{\circ} \mathrm{C}$ for $90 \mathrm{~s}$. High and low moisture groups with approximate moisture content of $9 \%$ and $6 \%$ were used. An impingement oven set at $100^{\circ} \mathrm{C}$ for 20 min was used as the control treatment. No treatment differed from control in terms of blanchability. A descriptive sensory shelf life study of six weeks found no evidence of oxidative changes in experimental treatments. The infrared blanched peanuts were roasted using an impingement oven set to $177^{\circ} \mathrm{C}$ for $10 \mathrm{~min}$ for a consumer acceptability test. Conventionally blanched peanuts roasted under the same parameters were used as a control. The consumer panel found the peanuts blanched by infrared radiation at $343^{\circ} \mathrm{C}$ for $60 \mathrm{~s}$ to be the most likeable roasted IR sample and did not differ from control. IR heating is a viable and quicker alternative to blanch small-sized peanut varieties with minimal effects on quality including sensory properties.
\end{abstract}

\section{Introduction}

There are three major peanut growing areas in the United States, the southeast region, the southwest region, and the Virginia-Carolinas region. Nine states account for $99 \%$ of all peanuts produced in the United States. Georgia (USA) contributes $\sim 45 \%$ to the US production [1]. The peanut industry contributes more than 50,000 jobs in Georgia (USA) and 23\% of the state's new row and forage crops income, underscoring the importance of this crop to the state's economy [2].

Removal of testa or the skin from peanut kernels is an important preprocessing step in processing peanuts into products such as peanut butter. This process is known as blanching and is achieved by the application of heat followed by the abrasive removal of the peanut skin while keeping the kernels intact. The resulting seedless kernels are still considered raw although they undergo a heat treatment. The various factors affecting the blanchability of peanuts include size and maturity of the peanut seeds, the conditions and length of storage after harvest and before processing, the genotype of the peanuts, and most importantly the moisture content of the kernels. The high rate of expansion for the peanut kernel compared with the expansion rate of the peanut skin causes more stress to be put on the peanut skin, which helps to loosen the peanut skin from the kernel. The resulting moisture loss and crisping of peanut skins will also aid fracturability and seed coat removal. The relatively high oil content of the peanut kernels is believed to cause a higher expansion rate for the kernels as well [3-6].

Today, there are several methods used for peanut blanching including microwave, dry, alkali, spin, water, and peroxide, although most of the research on blanching has been carried out on runner peanuts using hot air ovens [6]. In an extensive study carried out by Adelsberg and Sanders, medium commercial size, runner peanuts were blanched in an airflow direction controlled lab scale conventional hot air oven. The study took into account seed coat removed, moisture content reduction, and enzyme activity. Overall, it was found that the main factors affecting blanchability were initial moisture content, drying rate, and thermal expansion. Reduction in moisture content to less than $4 \%$ from an initial content of $5.5 \%$ resulted in a maximum blanchability of approximately $75 \%$. These results were produced using 


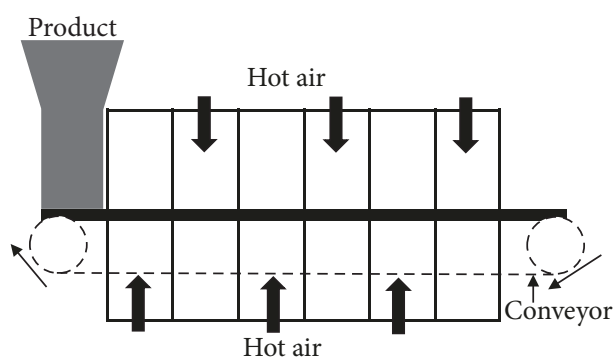

(a)

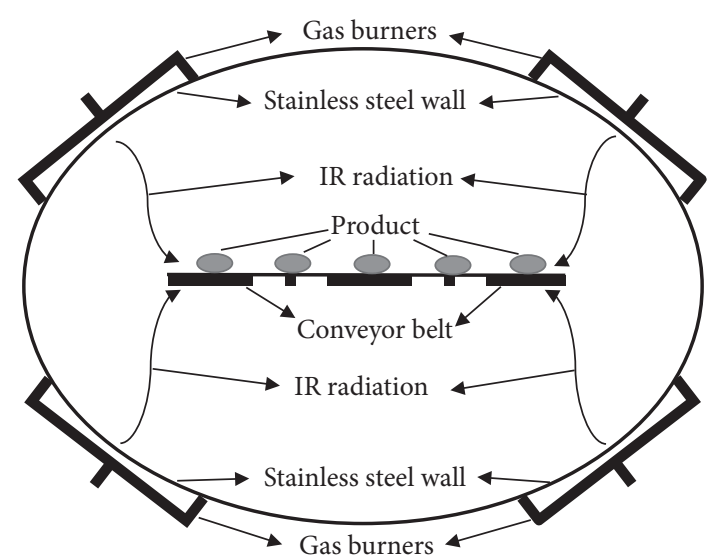

(b)

FIGURE 1: Schematic illustration of (a) hot air impingement oven (adapted from Adelsberg and Sanders, 1997) and (b) infrared heating in a radiant wall oven (adapted from Kettler et al., 2017).

a temperature of $87.7^{\circ} \mathrm{C}$ with times of 45 and $60 \mathrm{~min}$ and a temperature of $98.9^{\circ} \mathrm{C}$ with times of 40,45 , and $60 \mathrm{~min}$ [5]. Similarly, a continuous microwave technology has been researched for blanching, and it was observed that treatments that exceeded $110^{\circ} \mathrm{C}$ with a moisture content of $<5.5 \%$ resulted in $>85 \%$ blanchability, which is regarded as the industry standard. The study showed that microwave processing was a faster and more cost efficient process for peanut blanching [6]. Microwave technology is another example of radiative technology applied to food.

In the past decade or so infrared (IR) heating has been explored for food processing operations, including pasteurization, roasting, frying baking, drying, peeling, and blanching. IR heating is a form of radiative heating where the wavelength is determined by the temperature of the emitting body. This relationship is described by the basic laws of black body radiation. Black body radiation depends on the emitting body's temperature. IR radiation is a form of electromagnetic radiation that has a wavelength of 0.38 to $1000 \mu \mathrm{m}$. Generally, IR wavelengths that can be absorbed by food components are in the far-IR region of the spectrum from 3.0 to $1000 \mu \mathrm{m}$. The increasing popularity of this technology is due its energy efficiency, retention of quality in the finished products (mainly nutritional and sensory properties), process speed, and the simplicity of the equipment. IR heating is primarily done in radiant wall ovens where the heated walls emit IR radiation to apply heat to the material being processed [716]. Because IR heating is a surface level treatment, it is hypothesized that the skins from these peanuts may become more crisp and easier to remove.

Infrared blanching of large runner type peanuts has been explored in our lab in a previous study [17]. The study showed that IR blanching of large peanuts was possible with comparable rates of blanchability when compared to the traditional convection hot air oven method. It was observed that peanuts blanched using IR heating at $343^{\circ} \mathrm{C}$ for $1.5 \mathrm{~min}$, $316^{\circ} \mathrm{C}$ for $1.5 \mathrm{~min}, 288^{\circ} \mathrm{C}$ for $1.5 \mathrm{~min}$, and $343^{\circ} \mathrm{C}$ for $1 \mathrm{~min}$ did not differ significantly $(P>0.05)$ from the hot air controls. Figures 1(a) and 1(b) show the schematics for the conventional hot air heating method and the IR heating method, respectively. Additionally, in this study a sensory evaluation of shelf life was done with one control and three IR treated sampled and indications of possible initiation of oxidation for the conventionally blanched peanuts were found at 18 weeks of storage with no indication of oxidation in the IR treated samples [17].

The main objective of this research study was to determine the feasibility of using IR heating to blanch smallsized peanuts. Another objective was to measure oxidative changes, if any, in a short six-week shelf life study. The sixweek period was chosen because the peanut industry process blanched peanut kernels within a month's time [Personal Communication, Mr. Michael Woodall, Lewis M. Carter Manufacturing]. Finally, the blanched peanuts (both fresh and after four-week storage) were roasted to determine differences in acceptability, if any.

\section{Experimental}

2.1. Peanut Samples and Conditioning. Small size commercial grade peanuts were obtained from Lewis M. Carter Manufacturing (Donalsonville, GA). The peanuts were an aggregate of different peanut varieties that were sorted based on size [Personal Communication, Mr. Michael Woodall, Lewis M. Carter Manufacturing]. Once sorted, Peanuts were stored at $4^{\circ} \mathrm{C}$ until conditioned to two different moistures levels of approximately $6 \%$ and $9 \%$. These two moisture levels were chosen to simulate moisture levels consistent with freshly harvested peanuts (9\%) and peanuts that have been stored for a period of one year (6\%). Conditioning was done using a Hotpack Humidity Chamber (Model 155314; SP Scientific, Warminster, PA, USA) set at $90 \%$ relative humidity $(\mathrm{RH})$ and $40^{\circ} \mathrm{C}$ in approximately $14 \mathrm{~h}$ or until moisture analysis showed the peanuts had reached target moisture level.

2.2. Blanching. Peanut blanching was achieved by a conventional method using a conventional hot air impingement 


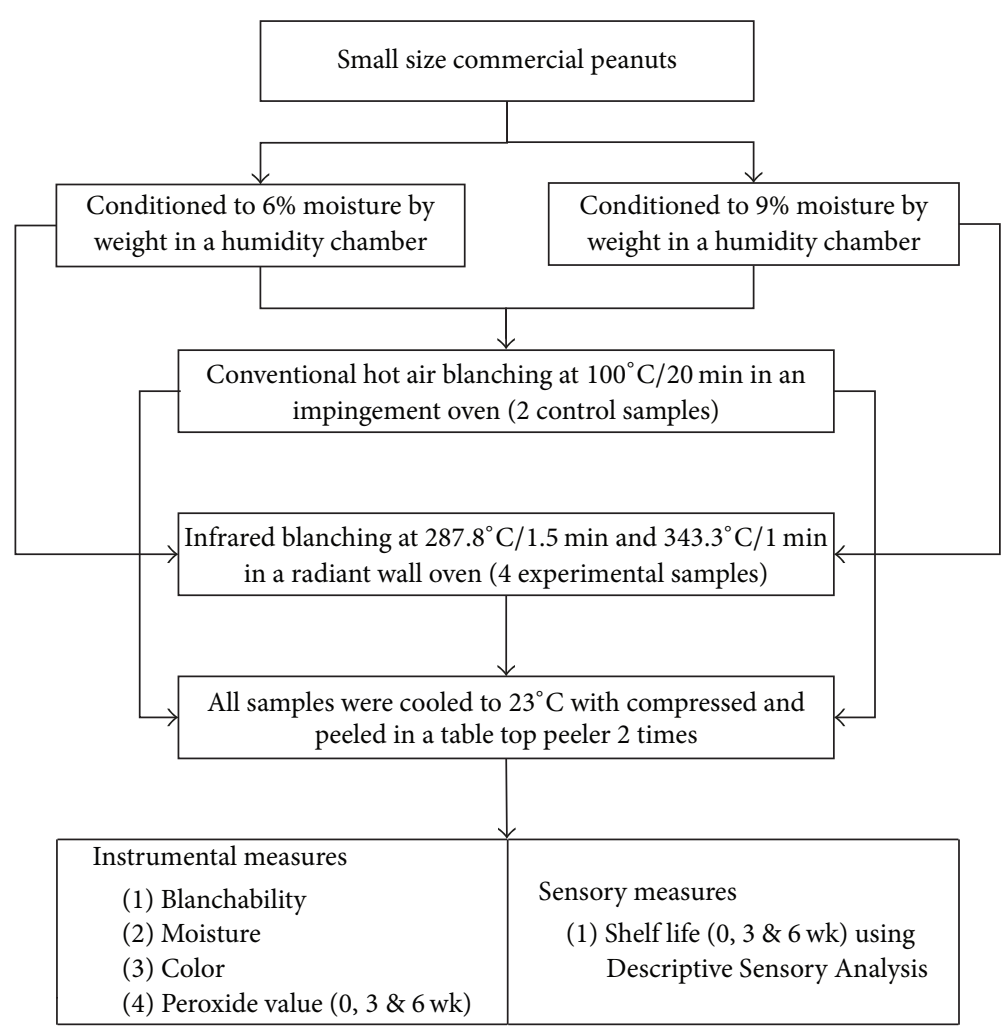

FIgURE 2: Flow chart outlining the blanching process.

TABLE 1: Description of blanching treatments $(n=3)$ used in the study.

\begin{tabular}{|c|c|c|c|c|}
\hline Treatment & $\begin{array}{l}\text { Initial moisture after } \\
\text { conditioning } \\
\text { (\%; wet weight basis ) }\end{array}$ & Oven type & $\begin{array}{c}\text { Temperature } \\
\left({ }^{\circ} \mathrm{C}\right)\end{array}$ & $\begin{array}{l}\text { Time } \\
\text { (min) }\end{array}$ \\
\hline Low moisture control & $5.93 \pm 0.71$ & Impingement & 100.0 & 20 \\
\hline Low moisture IR1 & $5.93 \pm 0.71$ & Radiant wall oven & 343.3 & 1 \\
\hline Low moisture IR2 & $5.93 \pm 0.71$ & Radiant wall oven & 287.8 & 1.5 \\
\hline High moisture control & $9.33 \pm 0.59$ & Impingement & 100.0 & 20 \\
\hline High moisture IR1 & $9.33 \pm 0.59$ & Radiant wall oven & 343.3 & 1 \\
\hline High moisture IR2 & $9.33 \pm 0.59$ & Radiant wall oven & 287.8 & 1.5 \\
\hline
\end{tabular}

oven (Model 1450; Lincoln Impinger, Fort Wayne, IN, USA) as a control, and an IR radiant wall oven (Model RWO12-26; Pyramid Food Processing Equipment Manufacturing, Tewksbury, MA, USA) for the IR method to be tested. Figure 1(a) illustrates the working of an impingement oven while Figure 1(b) shows the same for an IR radiant wall oven (RWO). Control samples processed in the impingement oven were blanched at $100^{\circ} \mathrm{C}$ for $20 \mathrm{~min}$ and samples processing in the IR RWO were blanched using two different time/temperature combinations, either $343.3^{\circ} \mathrm{C}$ for $1 \mathrm{~min}$ or $287.7^{\circ} \mathrm{C}$ for $1.5 \mathrm{~min}$ (Table 1 ). Peanuts were removed from cold storage and allowed to come to room temperature $\left(\sim 23^{\circ} \mathrm{C}\right)$. Peanuts that were split and peanuts without testa were removed from the supply before blanching. One kilogram of whole, unblanched peanuts was placed in custom-made $86.4 \mathrm{~cm} \times 28.6 \mathrm{~cm}$ perforated wire mesh trays in a single layer. Two trays were placed back to back per trial to process two kilograms of peanuts per batch. After processing, peanuts were immediately force cooled with compressed air to ambient temperatures $\left(23^{\circ} \mathrm{C}\right)$ for four minutes. The peanuts were then fed into a tabletop peeler (Model EX, Ashton Food Machinery Co., Newark, NJ, USA) with a top roller linear speed of $147.1 \mathrm{~m} / \mathrm{min}$ and a bottom roller linear speed of $147.9 \mathrm{~m} / \mathrm{min}$. Peanuts were run through the peeler twice to achieve maximum peeling. Three replicates were carried out for both the control and the experimental samples. A 20-gram sample/replicate was retained for moisture content determination before and after blanching. A 100gram sample/replicate was retained for color determination and oil extraction for peroxide value determination. Rest of the samples/replicate were frozen $\left(-15^{\circ} \mathrm{C}\right)$ for sensory shelf life testing. Figure 2 illustrates a flow chart outlining the 
blanching process including the moisture conditioning of the peanut kernels.

2.3. Roasting. The three low moisture peanut samples, two IR blanched $\left(343.3^{\circ} \mathrm{C}\right.$ for $1 \mathrm{~min}$ or $287.7^{\circ} \mathrm{C}$ for $1.5 \mathrm{~min}$ ) and one hot air blanched (control; $100^{\circ} \mathrm{C}$ for $20 \mathrm{~min}$ ), were roasted using a conventional hot air impingement oven (Model 1450, Fort Wayne, IN 46804, USA) to a CEI $L^{*}$ value of $\sim 48.5$, which indicates a medium roast level. All the three samples that were chosen for roasting based on their blanchability. In the blanching study, it was found that all the low moisture samples had higher blanchability than the high moisture samples. In order to investigate how storage time may change quality of roasted peanuts, once blanched, two different hold times were explored, a period of 1 day and a period of 30 days. Peanuts were held in sealed plastic bags at ambient temperature $\left(\sim 23^{\circ} \mathrm{C}\right)$ for 30 days. After the holding period, $750 \mathrm{~g}$ of blanched peanuts was placed in a custom-made $86.4 \mathrm{~cm} \times 28.6 \mathrm{~cm}$ perforated wire mesh tray in a single layer and roasted in the conventional hot air impingement oven at $177 \pm 1^{\circ} \mathrm{C}$ for $10 \mathrm{~min}$. The same roasting time and temperature were used for all the three samples. After roasting, the peanuts were immediately force cooled with compressed air to ambient temperature $\left(\sim 23^{\circ} \mathrm{C}\right)$ for $4 \mathrm{~min}$. Three replicates were carried for the all the three samples. A 100 gram sample/replicate was retained for color determination and moisture contented determination. A 250gram sample/replicate was retained from each trial for oil extraction for peroxide value determination. All other nuts blanched within the same sample for all three replicates were combined and used for testing of consumer acceptability test.

2.4. Instrumental Parameters. The instrumental measures were collected on all three processing trials for the both methods of blanching. The flow chart (Figure 2) also shows all the instrumental measures that were done on the blanched peanuts.

2.4.1. Blanchability Determination. A 100-gram sample was separated by hand based on visual inspection to determine blanchability. Peanuts were separated into blanched whole, blanched split, and unblanched nuts. Blanched whole and blanched split were added to arrive at the total blanched percentages. Peanuts were considered unblanched if seed coat was still visible on the peanut. Blanchability efficiency for all the treatments was determined manually as percentages.

2.4.2. Moisture Content. Twenty-gram samples were taken from each trial and ground using a small coffee grinder and analyzed in a HR73 Mettler-Toledo Halogen Moisture Analyzer (Mettler-Toledo, LLC, Columbus, OH, USA). Three to four grams of ground peanuts were weighed in the aluminum tray of the moisture analyzer and dried at $110^{\circ} \mathrm{C}$ for approximately six to ten minutes or until a consistent weight was achieved.

2.4.3. Color Determination. After determination of blanchability, the same 100-g sample was placed in a small Petri dish on a black background for color determination using a HunterLab MiniScan EZ Colorimeter (Hunter Associates Laboratory, Inc., Reston, VA, USA). This allows port of the device to be completely covered in peanuts while ensuring that no outside light interfered with measurements. Before use, the colorimeter was calibrated using black and white standardization tiles that were included with the device. Color was reported as CEI $L^{*}$ Values. Three measurements were taken per sample and averaged. Peanuts with $L^{*}$ values $>61$ are raw.

2.4.4. Peroxide Value. To measure the extent of oxidation and the possibility of off flavor formation in blanched and roasted peanuts, oil was extracted from the peanuts using a hydraulic Carver press (Carver Inc., Wabash, IN, USA). The resulting oil samples were transferred to 20 -mL glass vials wrapped in tin foil and kept frozen until analysis.

Peroxide value measurements were determined using the AOCS Official Method Cd 8-53. This method determines all substances, in terms of milliequivalents of peroxide per $1000 \mathrm{~g}$ of sample that oxidized potassium iodide (KI) under the conditions of the test. A $5.00 \pm 0.05 \mathrm{~g}$ sample of oil was measured and placed in a $250 \mathrm{~mL}$ glass stoppered Erlenmeyer flask. About $30 \mathrm{~mL}$ of an acetic acid-chloroform solution $(3: 2)$ was added to the flask and swirled until the sample was dissolved. Then, $0.5 \mathrm{~mL}$ of saturated KI solution was added to the flask using a volumetric pipet. After $1 \mathrm{~min}$, $30 \mathrm{~mL}$ of distilled water was added immediately to stop the reaction. This solution was then titrated against $0.1 \mathrm{~N}$ sodium thiosulfate under constant agitation with $2.0 \mathrm{~mL}$ of freshly prepared starch indicator to an endpoint of milky white color. Peroxide value is expressed as $\mathrm{mM}$ peroxide/1000 $\mathrm{g}$ oil sample.

$$
\begin{aligned}
& \text { Peroxide Value } \\
& =\frac{(S-B) \times \mathrm{N} \text { Sodium Thiosulfate } \times 1000}{\text { Weight of Sample }} .
\end{aligned}
$$

$S$ is titration of sample $(\mathrm{mL})$ and $B$ is titration of blank $(\mathrm{mL})$.

\subsection{Shelf Life Descriptive Sensory Analysis of Blanched} Peanuts. A trained panel comprising eight trained ( $>100 \mathrm{~h}$ of training and 1,200 h of testing) panelists was used to evaluate blanched nuts at the UGA Griffin campus. Approval from the university's IRB (Project ID MOD00002419) was obtained before undertaking the study. Samples for the shelf life study were stored in plastic containers at ambient temperature $\left(23^{\circ} \mathrm{C}\right)$ for 6 weeks. Peanuts were evaluated at 0,3 , and 6 weeks of storage. Panelists participated in a $2 \mathrm{~h}$ orientation prior to sensory evaluation. The descriptors evaluated were based on the peanut lexicon established by Johnsen et al. [18]. Descriptors and their definitions are shown in Table 2. Each descriptor was anchored with multiple references on a $0-15-$ point scale with 0.5 increments. At the beginning of each evaluation session panelist were calibrated using a warmup sample. For blind evaluations, samples were coded with 3 -digit random codes. The samples $(\sim 10 \mathrm{~g})$ were served to the panelists in a random order for evaluation in individual 
TABLE 2: Terms used in descriptive analysis of peanut treatments during the shelf life study.

\begin{tabular}{|c|c|c|c|}
\hline Descriptor & Modality & Definition & $\begin{array}{c}\text { Ratings of } \\
\text { warm-up sample }\end{array}$ \\
\hline Fracturability & Texture & The force with which you first bite through the sample & 6.5 \\
\hline Oiliness & Texture & Degree to which free oil is perceived in the mouth after 5 chews & 1 \\
\hline Raw/beany & Flavor & The flavor associated with raw peanuts & 3.5 \\
\hline Overall oxidized & Flavor & The old/stale flavor associated with rancid fats and oils & 0 \\
\hline Cardboard & Flavor & $\begin{array}{l}\text { The flavor associated with somewhat oxidized fats and oils and } \\
\text { reminiscent of wet cardboard }\end{array}$ & 0 \\
\hline Fishy & Flavor & $\begin{array}{l}\text { The flavor associated with trimethylamine, cod liver oil or old } \\
\text { fish }\end{array}$ & 0 \\
\hline Painty & Flavor & The aromatic associated with linseed oil, or oil based paint & 0 \\
\hline Bitter & Basic taste & $\begin{array}{l}\text { The taste on the tongue associated with bitter agents such as } \\
\text { caffeine solution }\end{array}$ & 1 \\
\hline Salty & Basic taste & $\begin{array}{l}\text { The taste on the tongue associated with sodium chloride } \\
\text { solution }\end{array}$ & 1 \\
\hline Sweet & Basic taste & The taste on the tongue associated with sucrose solution & 2 \\
\hline Astringent & Feeling factor & $\begin{array}{l}\text { The puckering or drying sensation on the mouth or tongue } \\
\text { surface }\end{array}$ & 1.5 \\
\hline
\end{tabular}

TABLE 3: Mean moisture content (\% wet weight basis; before and after blanching) and lightness values (CIE $L^{*}$; after blanching) of peanuts for the various treatments.

\begin{tabular}{lccr}
\hline Treatment & Initial moisture & Final moisture & $L^{*}$ \\
\hline Low moisture control & $5.93 \pm 0.71$ & $4.52 \pm 0.87$ & $67.31 \pm 2.70$ \\
Low moisture IR1 & $5.93 \pm 0.71$ & $5.39 \pm 0.58$ & $67.99 \pm 0.26$ \\
Low moisture IR2 & $5.93 \pm 0.71$ & $5.47 \pm 0.53$ & $68.25 \pm 0.80$ \\
\hline High moisture control & $9.33 \pm 0.59$ & $5.52 \pm 0.68^{\mathrm{b}}$ & $66.41 \pm 1.30$ \\
High moisture IR1 & $9.33 \pm 0.59$ & $7.60 \pm 0.19^{\mathrm{a}}$ & $65.04 \pm 1.76$ \\
High moisture IR2 & $9.33 \pm 0.59$ & $7.86 \pm 0.52^{\mathrm{a}}$ & $64.00 \pm 1.69$ \\
\hline
\end{tabular}

Means with different letters in a section column are statistically significant at $P<0.05$.

booths. The data was collected using Compusense Cloud (Compusense Inc., Guelph, Ontario, Canada) software.

2.6. Consumer Study of Roasted Peanuts. Roasted peanuts were subjected to an acceptability test with 79 participants that were screened based on peanut product usage. Approval from the university's IRB (Project ID MOD00002419) was obtained before undertaking the study. Both liking (liking of appearance, roasted peanut, sweetness, texture, and overall liking) and intensity (intensity of bitterness and stale flavor) questions were asked in the test. A 9-point hedonic scale ( $1=$ dislike extremely to $9=$ like extremely) was used for the liking questions while a 9-point category scale was used for the intensity questions. Three demographic questions on peanut consumption were also asked. Data was collected on paper ballots.

2.7. Statistical Analysis. One-way and two-way Analysis of Variance (ANOVA) were used to analyze the data in this experiment using the GLM Procedure in the SAS software (Version 9.4, SAS Institute, Cary, NC). Means comparison was completed using Tukey's HSD procedure. Principal
Component Analysis (PCA) was performed using XLSTAT (Version 2016, Addinsoft, New York, NY).

\section{Results and Discussion}

3.1. Instrumental Parameters. Moisture change after blanching for both control treatments was significantly different $(P<0.05)$ from the IR heated samples within the same moisture category (Table 3 ). Because these samples were blanched using the conventional hot air blanching method, which required much longer time, the moisture change was greater $(23.8-40.8 \%$ by weight based on the initial moisture content). IR samples did not experience significant amounts of moisture loss (9.1-15.8\% by weight based on the initial moisture content) because IR heating is largely a surface only treatment, which took much less time and thus did not remove much water from the peanuts. High moisture loss should correlate with higher rates of blanchability for peanuts that lost more moisture because moisture loss is the most important factor that affects blanchability [6]. The CIE $L^{*}$ value is an indicator of the degree of roasting of peanuts. For all samples, $L^{*}$ values were $>61(64.00-68.25)$ indicating that all samples were still considered to be raw after blanching 
TABLE 4: Blanching results (\%) for the treatment combinations used in this study.

\begin{tabular}{lcccc}
\hline Treatment & Blanched whole & Blanched split & Unblanched & Total blanched \\
\hline Low moisture control & $62.91 \pm 6.51$ & $21.62 \pm 3.30$ & $15.47 \pm 5.46$ & $84.53 \pm 5.46$ \\
Low moisture IR1 & $63.91 \pm 3.01$ & $23.99 \pm 2.57$ & $12.09 \pm 2.59$ & $87.91 \pm 2.59$ \\
Low moisture IR2 & $65.22 \pm 3.52$ & $22.20 \pm 6.16$ & $12.59 \pm 3.10$ & $87.41 \pm 3.10$ \\
\hline High moisture control & $58.79 \pm 14.35$ & $20.84 \pm 3.56$ & $20.37 \pm 13.02$ & $79.63 \pm 13.02$ \\
High moisture IR1 & $55.69 \pm 12.44$ & $19.08 \pm 4.40$ & $25.24 \pm 9.96$ & $74.76 \pm 9.96$ \\
High moisture IR2 & $57.87 \pm 13.46$ & $22.93 \pm 3.70$ & $19.20 \pm 10.80$ & $80.80 \pm 10.80$ \\
\hline
\end{tabular}

No significant differences found within the two moisture categories at $P=0.05$.

TABLE 5: Peroxide values of the blanched peanut samples.

\begin{tabular}{lccr}
\hline Treatment & \multicolumn{2}{c}{ Peroxide value $(\mathrm{mM} / \mathrm{kg})$} & Week 6 \\
\hline Low moisture control & Week 0 & $5.33 \pm 2.32$ & $5.98 \pm 5.26$ \\
Low moisture IR1 & $4.65 \pm 1.15$ & $6.68 \pm 3.06$ & $7.34 \pm 3.05$ \\
Low moisture IR2 & $3.99 \pm 2.02$ & $4.66 \pm 1.16$ & $4.68 \pm 1.16$ \\
\hline High moisture control & $3.98 \pm 1.98$ & $5.31 \pm 1.13$ & $5.98 \pm 3.43$ \\
High moisture IR1 & $3.99 \pm 3.45$ & $5.99 \pm 3.47$ & $6.62 \pm 3.02$ \\
High moisture IR2 & $4.64 \pm 1.15$ & $3.99 \pm 0.00$ & $3.99 \pm 1.98$ \\
\hline
\end{tabular}

No significant difference found at $P<0.05$.

(Table 3). An $L^{*}$ value greater than 61 is the standard that indicates an under roasted or raw peanut $[19,20]$.

The blanchability results (Table 4) showed no statistical differences among the six treatments, although it was observed that the percent total blanched was higher for the low moisture (6\%) control and IR treatments (84.53-87.91\%) compared to the high moisture (9\%) treatments $(74.76-80.80 \%)$. Similarly, the number of blanched whole kernels was higher for the low moisture treatments. In industry, the standard for blanchability has been determined to be $>85 \%$ and the low moisture treatments in this study were comparable to the industry standard [6]. Previous studies on blanching using the conventional hot air oven for times from 30 to $60 \mathrm{~min}$ produced blanchabilities between $71 \%$ and $75 \%$ with $2.94 \%$ being the lowest final moisture content [5]. Study on the use of IR heating for blanching large runner peanuts found blanchabilities to be between $76 \%$ and $86 \%$ [17]. As previously mentioned, the largest driving force in determining blanchability is moisture loss [6]. The lower amount of moisture loss in the IR blanched peanut kernels in this study is most likely due to the surface level heating of the IR treatments and the much lower processing times. Processing times for IR treatments were either 1 or $1.5 \mathrm{~min}$ compared to the $20 \mathrm{~min}$ for the control treatments or the 30 to $60 \mathrm{~min}$ as the industry standard.

In this study, peroxide values (Table 5) ranged between 3.98 and $7.34 \mathrm{mM} / \mathrm{kg}$ oil when the entire storage period of six weeks was considered. Although the peroxide values increased slightly over the course of the study, all values in IR treatments were below the limits set forth by the international standards for oils free of rancidity. International food standards as set by the Codex Alimentarius Commission state that fats and oils that are free from foreign and rancid odors and tastes should not exceed peroxide value of $10 \mathrm{mM} / \mathrm{kg}$ oil [21].
3.2. Shelf Life Descriptive Sensory Analysis of Blanched Peanuts. Oxidative changes followed by oxidized, cardboard, painty, and fishy flavors are the most common deteriorative defect in high fat products such as peanuts. The main reason for oxidative changes in peanuts is the autoxidation of linoleic acid, which is also known as flavor reversion [22, 23]. The shelf life descriptive study results (Table 6) showed no indication of any oxidative changes in any of the samples over the storage period of six weeks $(<0.33$ on a scale of 15$)$. This result is also supported by the peroxide values for the samples as noted in the previous section. In the study by Kettler et al., none of the IR blanched samples developed any oxidative notes when stored for 18 weeks at room temperature $\left(\sim 23^{\circ} \mathrm{C}\right)$. At the six-week mark, none of the samples had any off flavor due to oxidative changes [17]. In another similar descriptive shelf life study of 28 weeks, there were no perceived statistically significant differences found between blanched and unblanched peanuts stored at $26^{\circ} \mathrm{C}$ [24].

The most variable attribute in the samples over time was fracturability. Over time, fracturability increased in all the samples, especially in the low moisture samples. The average increase in fracturability across all the six samples was 0.96 (range: 0.48 to 1.40 ) on a scale of 15 . This was probably due to some loss in moisture during storage. No differences were found in the oiliness or raw/beany character of any group at any time. These two attributes are normal positive attributes associated with raw peanuts.

3.3. Consumer Study of Roasted Peanuts. Seventy-nine consumers participated in the study, out which 43 were male and 36 were female participants. Seventy-two percent of the respondents were under the age of 55 years. Around $50 \%$ of the participants consumed peanuts or peanut products $2-3$ times a week. Roasted peanuts (71\%) and peanut butter (68\%) 


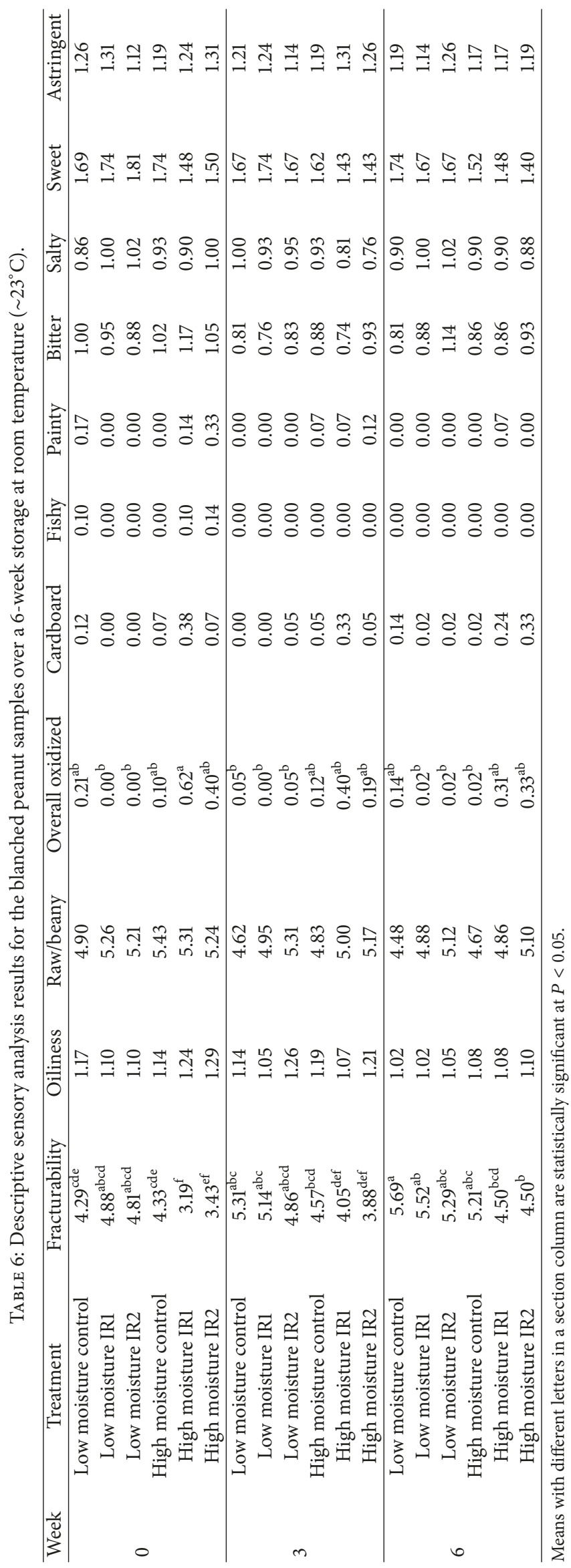


TABLE 7: Consumer $(n=79)$ acceptability study results for roasted peanuts.

\begin{tabular}{|c|c|c|c|c|c|c|c|c|c|}
\hline Treatment & $\begin{array}{l}\text { Holding } \\
\text { period }\end{array}$ & $\begin{array}{l}\text { Appearance } \\
\text { liking }\end{array}$ & $\begin{array}{c}\text { Roasted } \\
\text { peanut } \\
\text { liking }\end{array}$ & $\begin{array}{c}\text { Sweetness } \\
\text { liking }\end{array}$ & $\begin{array}{c}\text { Texture } \\
\text { liking }\end{array}$ & $\begin{array}{c}\text { Overall } \\
\text { liking }\end{array}$ & $\begin{array}{l}\text { Bitterness } \\
\text { intensity }\end{array}$ & $\begin{array}{l}\text { Staleness } \\
\text { intensity }\end{array}$ & $\begin{array}{c}\text { Consumers } \\
\text { who } \\
\text { detected } \\
\text { staleness }\end{array}$ \\
\hline Control & 1 day & $5.10^{\mathrm{ab}}$ & $5.84^{\mathrm{a}}$ & $5.44^{\mathrm{a}}$ & $6.35^{\mathrm{a}}$ & $5.49^{\mathrm{a}}$ & $4.73^{\mathrm{ab}}$ & $1.13^{\mathrm{b}}$ & $19 / 79$ \\
\hline IR1 & 1 day & $5.32^{\mathrm{a}}$ & $5.94^{\mathrm{a}}$ & $5.19^{\mathrm{ab}}$ & $6.37^{\mathrm{a}}$ & $5.53^{\mathrm{a}}$ & $4.29^{\mathrm{b}}$ & $1.00^{\mathrm{b}}$ & $17 / 79$ \\
\hline IR2 & 1 day & $4.59^{\mathrm{b}}$ & $4.80^{\mathrm{b}}$ & $4.46^{\mathrm{c}}$ & $5.70^{\mathrm{b}}$ & $4.42^{\mathrm{c}}$ & $5.25^{\mathrm{a}}$ & $2.43^{\mathrm{a}}$ & $37 / 79$ \\
\hline Control & 30 days & $4.62^{\mathrm{b}}$ & $5.25^{\mathrm{ab}}$ & $4.63^{\mathrm{bc}}$ & $5.96^{\mathrm{ab}}$ & $4.70^{c}$ & $5.14^{\mathrm{ab}}$ & $1.75^{\mathrm{ab}}$ & $29 / 79$ \\
\hline IR1 & 30 days & $5.48^{\mathrm{a}}$ & $5.34^{\mathrm{ab}}$ & $5.00^{\mathrm{abc}}$ & $6.29^{\mathrm{a}}$ & $5.13^{\mathrm{abc}}$ & $4.59^{\mathrm{ab}}$ & $1.49^{\mathrm{ab}}$ & $24 / 79$ \\
\hline IR2 & 30 days & $5.51^{\mathrm{a}}$ & $5.66^{\mathrm{a}}$ & $4.96^{\mathrm{abc}}$ & $6.16^{\mathrm{ab}}$ & $5.20^{\mathrm{ab}}$ & $4.61^{\mathrm{ab}}$ & $1.65^{\mathrm{ab}}$ & $23 / 79$ \\
\hline
\end{tabular}

Means with different letters in a section column are statistically significant at $P<0.05$.

were the most popular forms of product consumed, followed by boiled peanuts ( $41 \%)$ and peanut bars (37\%).

Scores for overall liking show that control and IR 1 without any holding were the most liked samples with very similar score (Table 7), while IR 2 without any holding time was the least liked sample. Consumers (37/79) detected a higher intensity of staleness in IR2 (1-day hold), which was an anomaly that could not be explained, although the peroxide value $(10 \mathrm{mM} / \mathrm{kg}$ of oil) was also the highest in this sample. All samples that were held for 30 days before roasting were in between the most and least liked samples while the control for 30 days of holding had a score of less than five. Some specific aspects that are of concern and may contribute to the variations in liking score were the intensities of bitter and stale flavors. Although all the samples were roasted to medium roast levels $\left(L^{*} \sim 48.5\right)$, it may have been a higher level of roast for the small-sized peanuts. This reflected in the bitterness intensity scores (4.59-5.25) and the overall liking scores (4.42-5.53) and from the comments of the participants who indicated that the peanut samples were overroasted. The liking score of the control treatment and IR 1 was lower for the 30-day stored blanched peanuts, while the score improved a little for the IR2 (30-day hold). Liking scores that are less than 6 indicate that consumers had a degree of disliking for samples and might indicate the presence of oxidative byproducts and Maillard reaction products giving the samples some staleness and bitterness, respectively $[25,26]$. Overall, it can be stated that the differences in acceptability were minimal between the controls and the IR blanched peanuts that were either freshly roasted (1-day hold) or roasted after a 30-day hold.

\section{Conclusions}

Infrared heating is a viable alternative to conventional blanching. Blanchability results and data from the descriptive shelf life study of blanched peanuts were consistent with results seen in other studies. The best outcomes in blanching were a result at heating to $287.8^{\circ} \mathrm{C}$ for $90 \mathrm{~s}$. When applied to peanuts with lower initial moisture content of approximately $6 \%$ this treatment results in the best blanchability while limiting off flavor formation. The result stated above indicates that a high temperature and short time treatment with low initial moisture content $(<6 \%)$ might be the best option if IR heating is to be applied to peanut blanching. Although the sensory data from the shelf life study of the blanched peanuts had the best results with a low temperature for longer time, the high temperature short time method results had only minor differences.

Peanuts blanched using IR technology that were subsequently roasted by conventional method were comparable to their counterparts. Ideally, peanuts should be roasted directly after blanching to achieve the highest likeability and acceptance. However, a 30-day storage period did not change acceptability much. In future, an all-infrared blanching and roasting methods could be explored with small-sized peanuts.

\section{Disclosure}

First author is Ms. Catherine Smith.

\section{Conflicts of Interest}

The authors declare no conflicts of interest.

\section{Acknowledgments}

The authors thank Mr. Michael Woodall (Director, Research \& Development, Lewis M. Carter Manufacturing) for supplying the peanut samples and Mr. Carl Ruiz and Mr. Glenn Farrell for help during experimental phase of this study. Thanks are also due to Ms. Paula Scott for managing the descriptive sensory panel used in the shelf life study and for administering the consumer acceptability test.

\section{References}

[1] P. Archer, "Overview of the peanut industry supply chain," in Peanuts Genetics, Processing, and Utilization, H. T. Stalker and R. F. Wilson, Eds., pp. 253-265, Academic Press and AOCS Press, New York, NY, USA, 2016.

[2] Georgia Peanut Commission. (2016). About Us. http://www .gapeanuts.com/about_us.php.

[3] M. R. Paulsen and G. H. Brusewitz, "Coefficient of cubical thermal -expansion for spanish peanut kernels and skins," Transactions of the ASAE, vol. 19, no. 3, pp. 0592-0595, 1976. 
[4] E. H. Shokraii, A. Esen, and R. W. Mozingo, "Relation of a 36 000-Dalton Arachin Subunit to Blanchability in Peanuts (Arachis hypogaea L.)," Journal of Agricultural and Food Chemistry, vol. 33, no. 6, pp. 1114-1116, 1985.

[5] G. D. Adelsberg and T. H. Sanders, "Effect of Peanut Blanching Protocols on Bed and Seed Temperatures, Seed Moisture, and Blanchability ," Peanut Science, vol. 24, no. 1, pp. 42-46, 1997.

[6] A. V. Schirack, T. H. Sanders, and K. P. Sandeep, "Effect of processing parameters on the temperature and moisture content of microwave-blanched peanuts," Journal of Food Process Engineering, vol. 30, no. 2, pp. 225-240, 2007.

[7] K. Krishnamurthy, H. K. Khurana, J. Soojin, J. Irudayaraj, and A. Demirci, "Infrared heating in food processing: An overview," Comprehensive Reviews in Food Science and Food Safety, vol. 7, no. 1, pp. 2-13, 2008.

[8] Y.-P. Lin, T.-Y. Lee, J.-H. Tsen, and V. A.-E. King, "Dehydration of yam slices using FIR-assisted freeze drying," Journal of Food Engineering, vol. 79, no. 4, pp. 1295-1301, 2007.

[9] N. K. Rastogi, "Recent trends and developments in infrared heating in food processing.", Critical Reviews in Food Science and Nutrition, vol. 52, no. 9, pp. 737-760, 2012.

[10] G. C. Jeevitha, H. Umesh Hebbar, and K. S. M. S. Raghavarao, "Electromagnetic radiation-based dry blanching of red bell peppers: A comparative study," Journal of Food Process Engineering, vol. 36, no. 5, pp. 663-674, 2013.

[11] G. Bingol, B. Wang, A. Zhang, Z. Pan, and T. H. McHugh, "Comparison of water and infrared blanching methods for processing performance and final product quality of French fries," Journal of Food Engineering, vol. 121, no. 1, pp. 135-142, 2014.

[12] X. Li and Z. Pan, "Dry Peeling of Tomato by Infrared Radiative Heating: Part II. Model Validation and Sensitivity Analysis," Food and Bioprocess Technology, vol. 7, no. 7, pp. 2005-2013, 2014.

[13] B. Wu, Z. Pan, W. Qu, B. Wang, J. Wang, and H. Ma, "Effect of simultaneous infrared dry-blanching and dehydration on quality characteristics of carrot slices," LWT-Food Science and Technology, vol. 57, no. 1, pp. 90-98, 2014.

[14] B. Kirmaci and R. K. Singh, "Quality of the pre-cooked potato strips processed by Radiant Wall Oven," LWT-Food Science and Technology, vol. 66, pp. 565-571, 2016.

[15] M. H. Riadh, S. A. B. Ahmad, M. H. Marhaban, and A. C. Soh, "Infrared heating in food drying: an overview," Drying Technology, vol. 33, no. 3, pp. 322-335, 2015.

[16] C. Sandu, "Infrared Radiative Drying in Food Engineering: A Process Analysis," Biotechnology Progress, vol. 2, no. 3, pp. 109119, 1986.

[17] K. Kettler, K. Adhikari, and R. K. Singh, "Blanchability and sensory quality of large runner peanuts blanched in a radiant wall oven using infrared radiation," Journal of the Science of Food and Agriculture, vol. 97, no. 13, pp. 4621-4628, 2017.

[18] P. B. Johnsen, G. V. Civille, J. R. Vercellotti, T. H. Sanders, and C. A. Dus, "Development of a lexicon for the description of peanut flavor," Journal of Sensory Studies, vol. 3, no. 1, pp. 9-17, 1988.

[19] K. A. Mcdaniel, B. L. White, L. L. Dean, T. H. Sanders, and J. P. Davis, "Compositional and Mechanical Properties of Peanuts Roasted to Equivalent Colors using Different Time/Temperature Combinations," Journal of Food Science, vol. 77, no. 12, pp. C1293-C1299, 2012.

[20] A. L. Smith and S. A. Barringer, "Color and volatile analysis of peanuts roasted using oven and microwave technologies," Journal of Food Science, vol. 79, no. 10, pp. C1895-C1906, 2014.
[21] Codex Stan 19-1981, "Codex standards for edible fats and oils not covered by individual standards," Codex Alimentarius: International Food Standards, FAO (UN) and WHO, Amendment: 2015.

[22] A. V. Schirack, M. Drake, T. H. Sanders, and K. P. Sandeep, "Impact of microwave blanching on the flavor of roasted peanuts," Journal of Sensory Studies, vol. 21, no. 4, pp. 428-440, 2006.

[23] C. G. Riveros, M. G. Mestrallet, M. F. Gayol, P. R. Quiroga, V. Nepote, and N. R. Grosso, "Effect of storage on chemical and sensory profiles of peanut pastes prepared with high-oleic and normal peanuts," Journal of the Science of Food and Agriculture, vol. 90, no. 15, pp. 2694-2699, 2010.

[24] T. H. Sanders, G. D. Adelsberg, K. W. Hendrix, and R. W. McMichael, "Effect of Blanching on Peanut Shelf-Life," Peanut Science, vol. 26, no. 1, pp. 8-13, 1999.

[25] N. R. Grosso and A. V. A. Resurreccion, "Predicting consumer acceptance ratings of cracker-coated and roasted peanuts from descriptive analysis and hexanal measurements," Journal of Food Science, vol. 67, no. 4, pp. 1530-1537, 2002.

[26] S. Wang, K. Adhikari, and Y.-C. Hung, "Acceptability and Preference Drivers of Freshly Roasted Peanuts," Journal of Food Science, vol. 82, no. 1, pp. 174-184, 2017. 


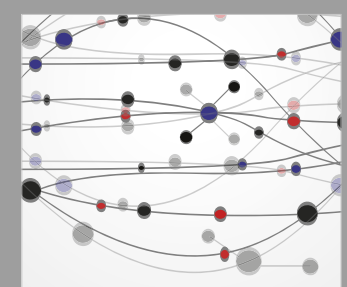

The Scientific World Journal
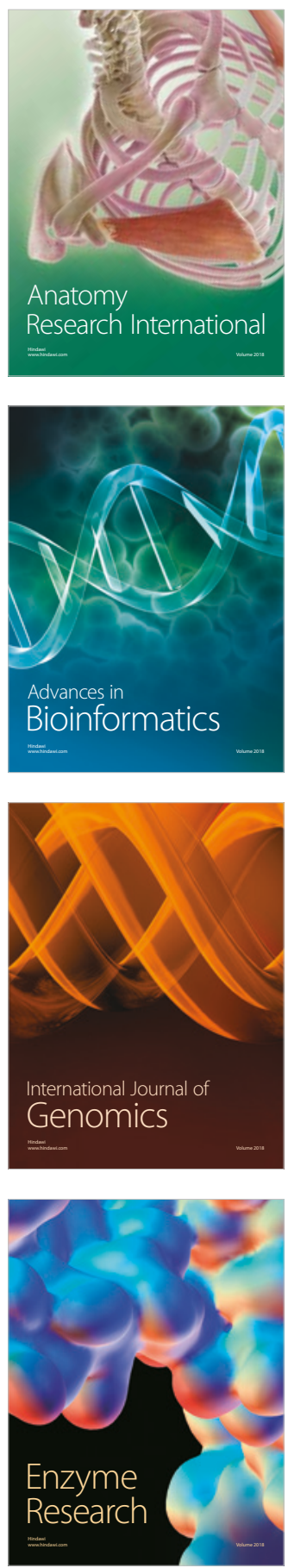
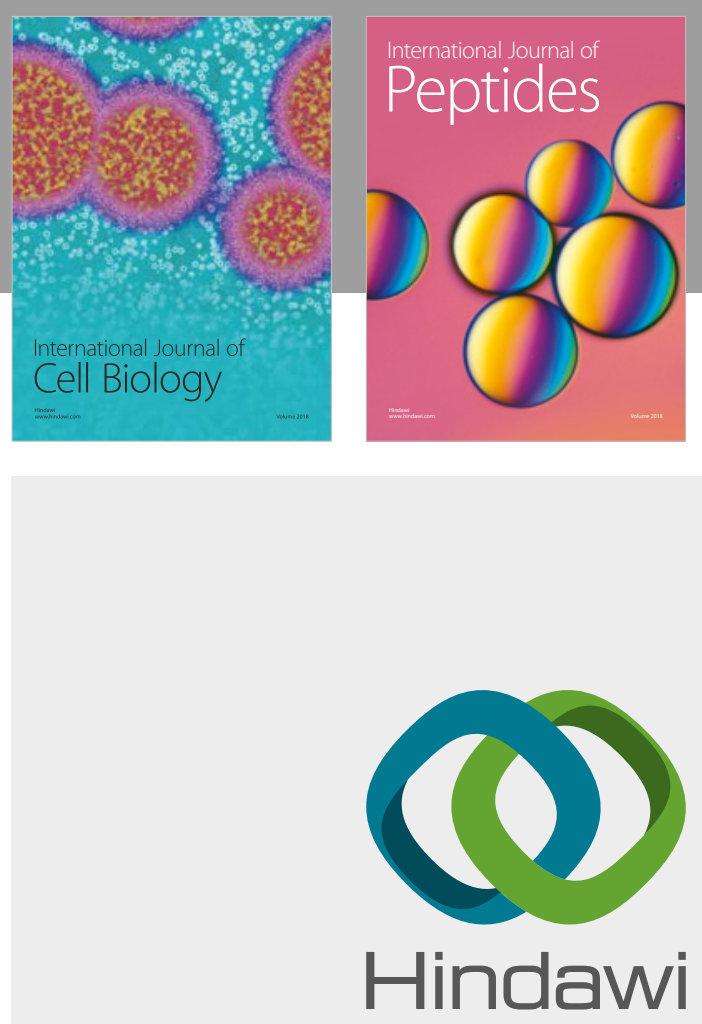

Submit your manuscripts at

www.hindawi.com
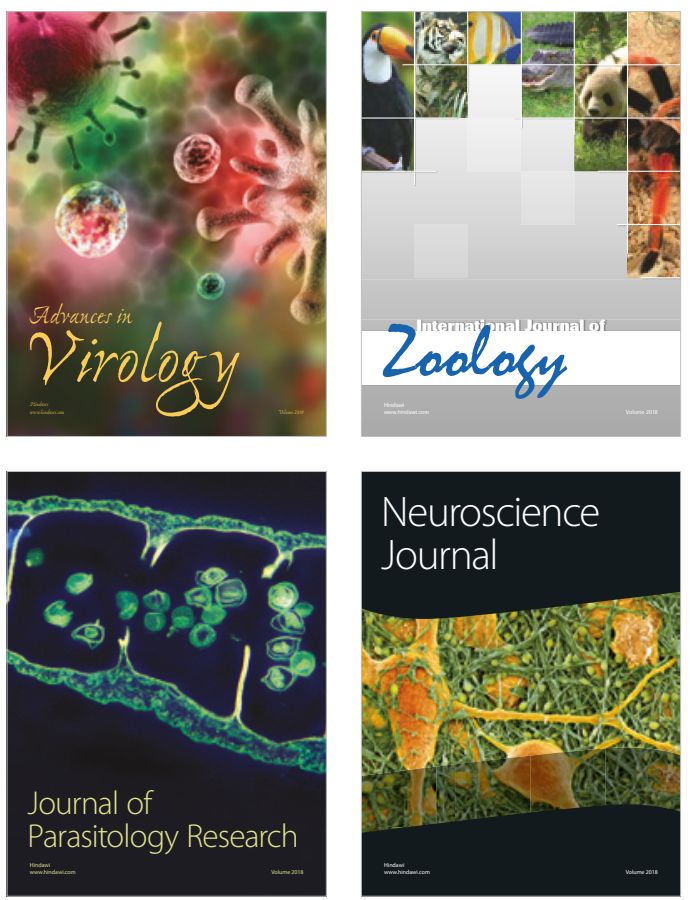
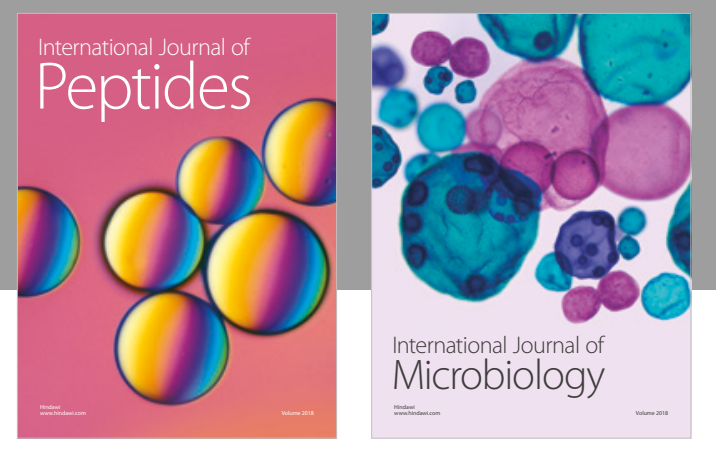

nternational Journal of Microbiology
Journal of
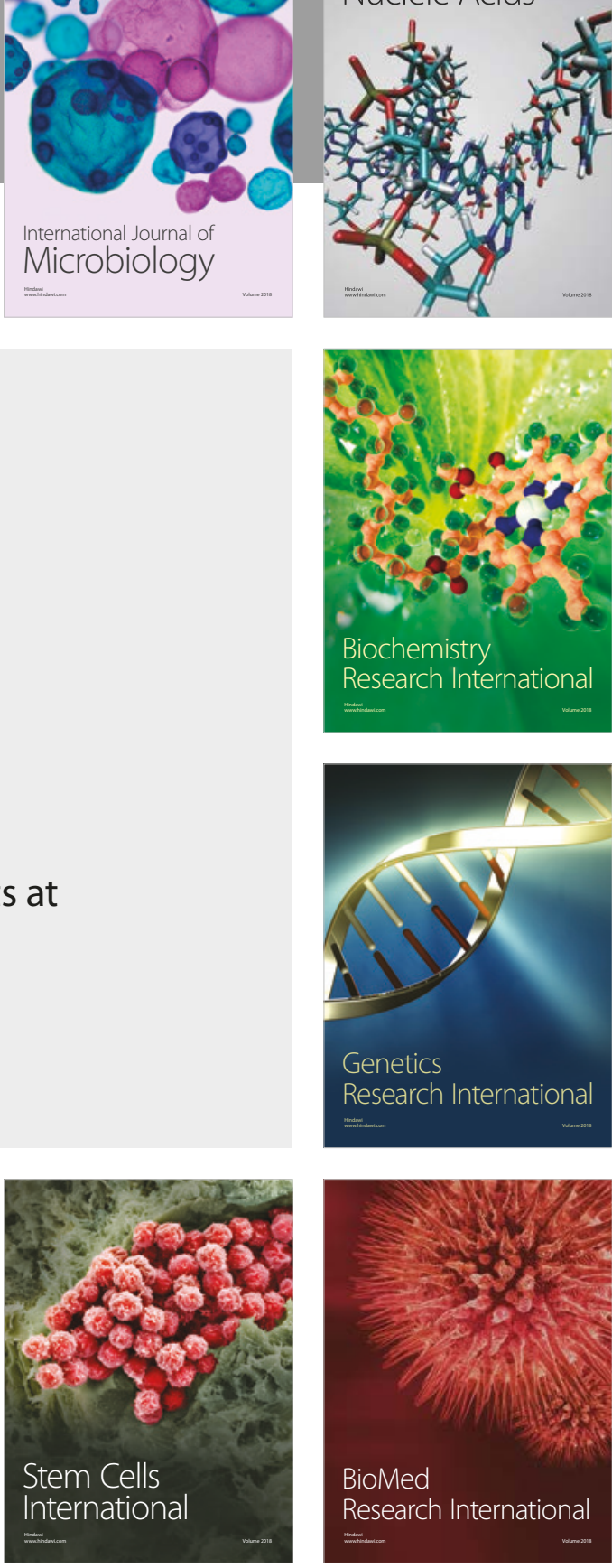
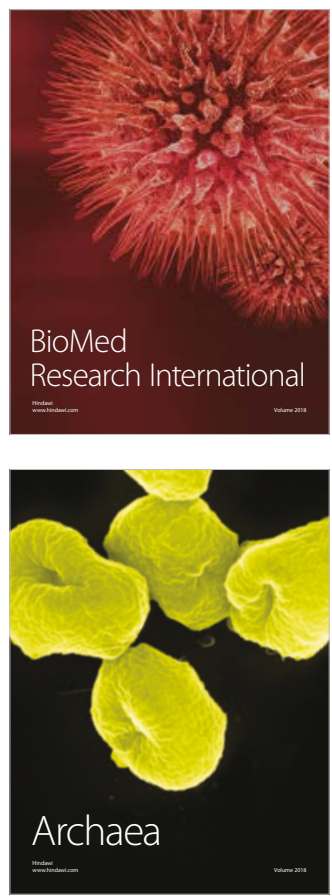